\title{
PEMANTAUAN KONDISI TUBUH BERBASIS ARDUINO DAN RASPBERRY PI UNTUK PENGENDALIAN KONDISI RUANGAN
}

\author{
Ahmad Sabiq, Nova Eka Diana, Debita Febriana \\ Teknik Informatika, Universitas YARSI, Jakarta \\ E-mail: ahmad.sabiq@yarsi.ac.id,nova.diana@yarsi.ac.id, debitafebriana@gmail.com
}

\begin{abstract}
A cozy room should adjust its environment based on the condition of its occupants since it will indirectly affect the moods and body conditions of people inside. This study aims to develop a system for monitoring the human body condition using paired sensors on the Arduino Lilypad. The system will send the sensors data to the Raspberry Pi3 via Bluetooth to automatically control the electronic device inside the room based on the occupant body condition. The developed system will automatically turn on or turn off the electronic device when the body temperature or the heart rate is higher than the specified threshold value.
\end{abstract}

Keywords: Lilypad, Raspberry, body sensor

\begin{abstract}
Abstrak
Kondisi tempat yang nyaman bagi setiap orang bisa berbeda-beda, tergantung kondisi tubuh yang sedang dialami oleh orang tersebut. Pengaruh kondisi fisik ruangan juga dapat mempengaruhi kondisi tubuh seseorang. Secara ideal, kondisi ruangan seharusnya dapat menyesuaikan dengan keadaan seseorang yang sedang menempati ruangan tersebut. Pada penelitian ini dikembangkan sistem pemantayan kondisi tubuh dengan menggunakan sensorsensor yang dipasangkan pada Arduino Lilypad. Data dari sensor akan dikirimkan melalu Bluetooth ke Raspberry Pi3 untuk melakukan pengendalian perangkat elektronik seperti kipas dan lampu secara otomatis sesuai keadaan seseorang. Dari hasil pengujian, perangkat elektronik seperti kipas dapat menyala atau mati jika suhu tubuh seseorang yang dipasang sensor melawati batasan teretentu, begitu juga dengan lampu yang dapat menyala atau mati jika detak jantung melawati batasan teretentu.
\end{abstract}

Kata Kunci: Lilypad, Raspberry, body sensor

\section{Pendahuluan}

Dalam kehidupan sehari-hari, manusia pada umumnya membutuhkan tempat yang nyaman untuk beraktifitas. Kondisi tempat yang nyaman bagi setiap orang bisa berbeda-beda, tergantung kondisi tubuh yang sedang dialami oleh orang tersebut. Pengaruh kondisi fisik ruangan juga dapat mempengaruhi kondisi tubuh seseorang. Secara ideal, kondisi ruangan seharusnya dapat menyesuaikan dengan keadaan seseorang yang sedang menempati ruangan tersebut.

Untuk memantau kondisi tubuh seseorang. terdapat teknologi Wireless Body Area Network (WBAN) yang saat ini sudah mulai dikembangkan. WBAN merupakan pengembangan dari teknologi Wireless Sensor Network (WSN) (Priyanka, R., Kamal D.S., Hakima C. dan Jean M.B. 2014) yang dikhususkan untuk memantau kondisi tubuh menggunakan sensor yang disebar di anggota tubuh manusia secara nirkabel (Salayma, Marwa, dkk, 2017). WBAN terdiri dari sensor yang menangkap informasi fisiologis dan mengirimkannya ke stasiun pusat atau sink melalui komunikasi nirkabel. WBAN dapat mengganti peralatan kesehatan yang kompleks dan terkomputerisasi karena dapat terus memantau statistik vital tubuh (Movassaghi et al. 2014). Perangkat sensor WBAN seharusnya memberi umpan balik real-time tanpa menimbulkan ketidaknyamanan, sehingga memberikan fleksibilitas dan mobilitas yang lebih besar kepada penggunanya (Otto,C dkk. 2006).

Untuk membangun sistem komputer yang menyatu dengan lingkungan, terdapat teknologi Pervasive Computing merupakan sebuah konsep yang membuat komputer mempengaruhi hidup, 
menyatu dan berinteraksi dengan lingkungannya (Maryam, N. N., Istiyanto, J. E., 2005), sehingga memungkinkan pengguna dengan atau tanpa sadar dapat berinteraksi secara langsung dengan perangkat komputer.

Pada penelitian ini, dikembangkan sebuah sistem pemantauan kondisi tubuh menggunakan Body Area Network (BAN) menggunakan Arduino Lilypad untuk mengatur kondisi ruangan seperti suhu, kelembapan ataupun cahaya.

\section{Metode Penelitian}

Penelitian yang dilakukan termasuk penelitian rekayasa teknologi, dimana penulis melakukan proses rekayasa dengan melakukan perancangan dari hasil studi literatur dan analisa kebutuhan dan melakukan implementasi sistem yang dirancang serta melakuakn pengujian sistem untuk mendapatkan data yang akan dianalisa untuk mengetahui kinerja dari sistem yang dibangun.

Pada gambar 1 ditunjukan rancangan sistem yang dibangun menggunakan perangkat Arduino Lilypad yang terhubung dengan sensor pada tubuh pengguna. Sensor tersebut memberikan data mengenai suhu dan detak jantung yang akan diterima oleh Arduino Lilypad, kemudian data tersebut dikirim melalui perangkat Bluetooth ke Raspberry Pi. Setelah data diterima oleh Raspberry Pi. Raspberry akan mengendalikan perangkat elektronik melalui Switch yang terhubung sesuai data kondisi tubuh yang diterima dari Arduino Lilypad.

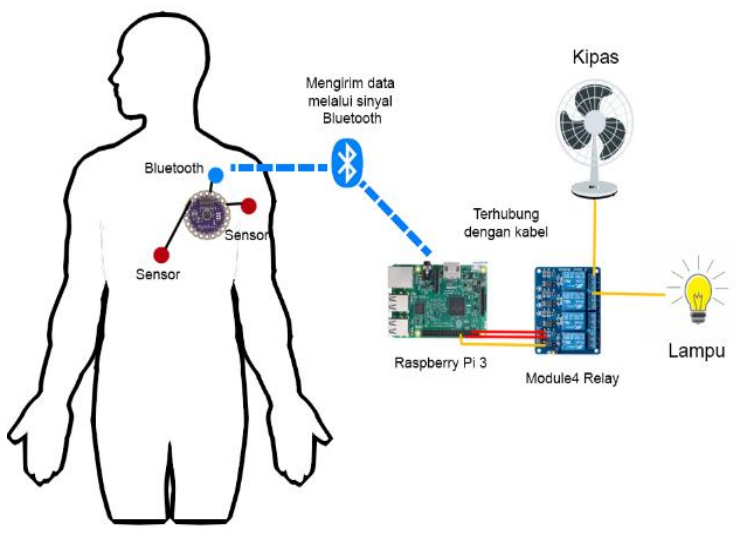

Gambar 1 Rancangan Sistem Pemantauan Kondisi Tubuh

\subsection{Rancangan Body Sensor}

Penulis menggunakan perangkat mikrokontoler Arduino Lilypad yang telah terpasang 3 sensor yaitu, Pulse Rate Heart Sensor, sensor DHT22 (suhu dan kelembapan), sensor DS18S20 (Waterproof Temperature Probe Sensor).

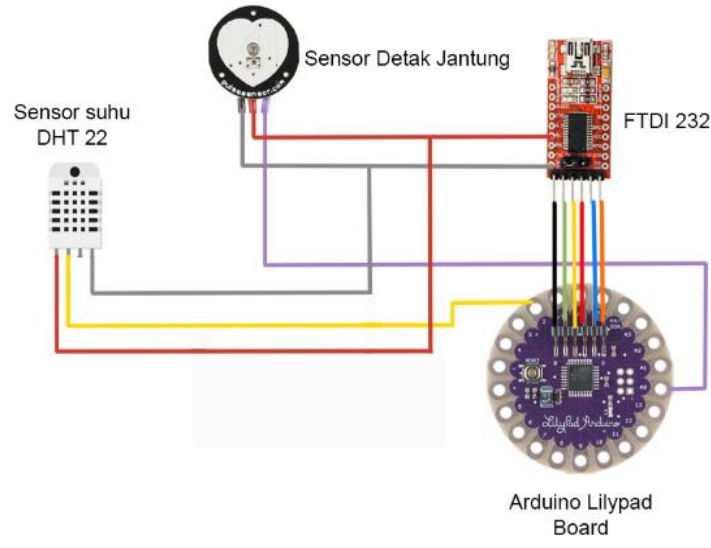

Gambar 2. Rancangan Sensor Pada Arduino Lilypad

Rangkaian Arduino Lilypad pada gambar 2 digunakan untuk implementasi pembuatan purwarupa sistem pemantauan kondisi tubuh yang akan dipasang pada pakaian. Pada rancangan tersebut 2 pin digunakan untuk menghubungkan sensor.

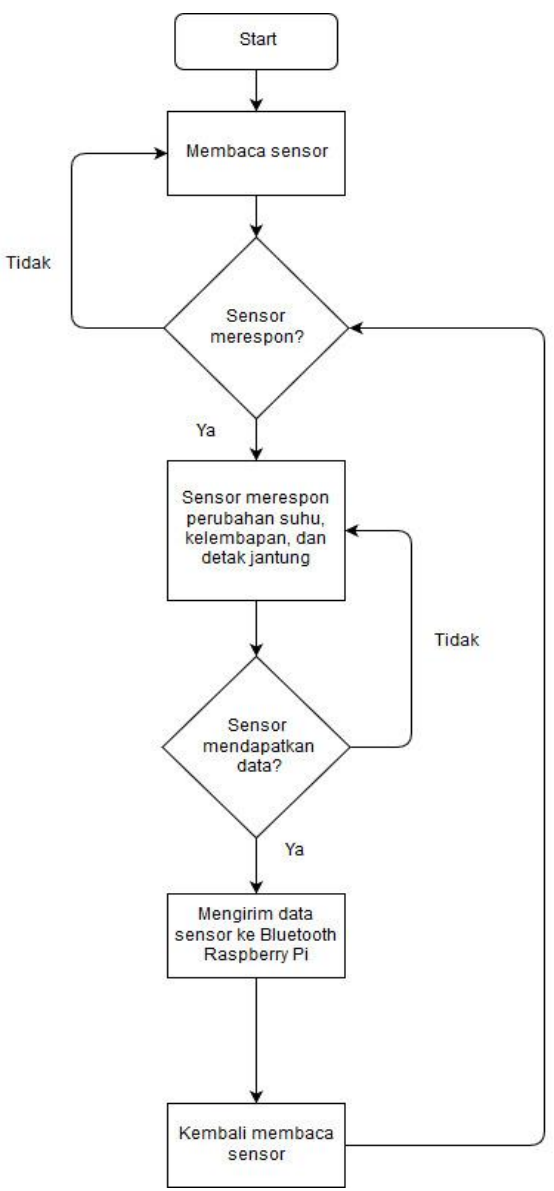

Gambar 3. Diagram Alir Rancangan Sensor.

Sensor terhubung melalui sumber arus listrik 5 volt dari Arduino Lilypad. Setiap sensor menangkap 
data yang berbeda, sensor Pulse Rate Heart berfungsi untuk menangkap data dari detak jantung seseorang, sensor DHT22 untuk mendeteksi suhu dan kelembapan udara di ruangan, dan sensor DS18S20 untuk sensor panas tubuh.

Pada gambar 3 ditunjukan diagram alir dari cara kerja sensor dalam mendeteksi dan mengirim data menggunakan Bluetooth. Pada tahap pertama Arduino akan membaca sensor yang terpasang, untuk tahap selanjutnya sensor akan merespon perubahan suhu, kelembapan dan detak jantung. Ketika sensor sudah mulai merespon dan mendapatkan data, tahap selanjutnya data tersebut akan dikirim melalui Bluetooth ke Raspberry Pi.

\subsection{Perancangan Pengendali Perangkat Elektronik pada Ruangan.}

Untuk penerima data dari Arduino Lilypad, penulis menggunakan perangkat Bluetooth yang terpasang pada Raspberry Pi 3 model B dan switch 4 Relay sebagai pengendali lampu ruangan dan kipas. Rancangan Raspberry Pi dan switch dapat dilihat pada gambar 4 .

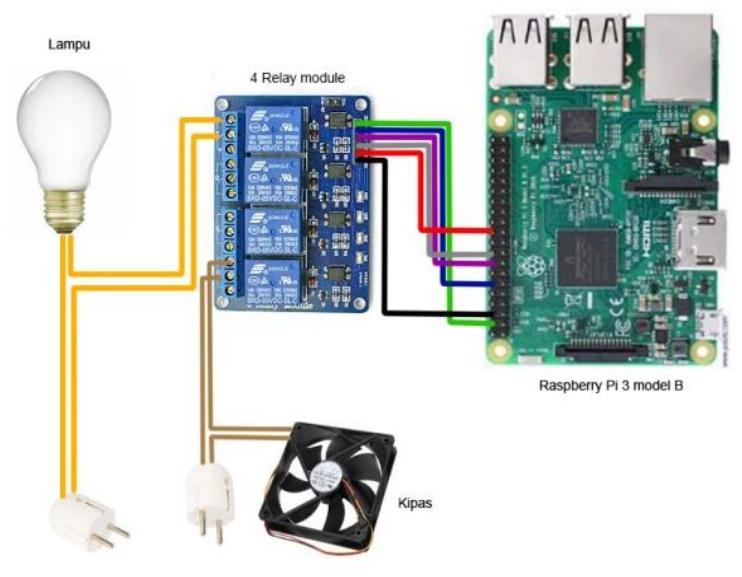

Gambar 4. Rancangan Raspberry Pi dan Switch

Perangkat elektronik yang akan dikendalikan, yaitu lampu dan kipas dihubungkan pada modul relay yang berfungsi sebagai switch On/Off. Switch tersebut dihubungkan ke Rapsberry Pi 3 model B untuk mengatur dan penerima perintah dari data yang telah dikirim.

Pada Raspberry Pi dibuatkan program dengan alur seperti diagram alir pada gambar 5. Saat pertama kali dihidupkan, program akan mencari sinyal Bluetooth dari Lilypad. Setelah koneksi Bluetooth dari Lilypad didapatkan, program akan menerima data sensor yang dikirimkan oleh Lilypad melalui sinyal Bluetooth.

Data yang didapatkan kemudian dibandingkan dengan kondisi perangkat elektronik, apakah dalam kondisi hidup atau mati, setelah itu program memberikan instruksi ke perangkat elektronik untuk dinyalakan atau dimatikan.

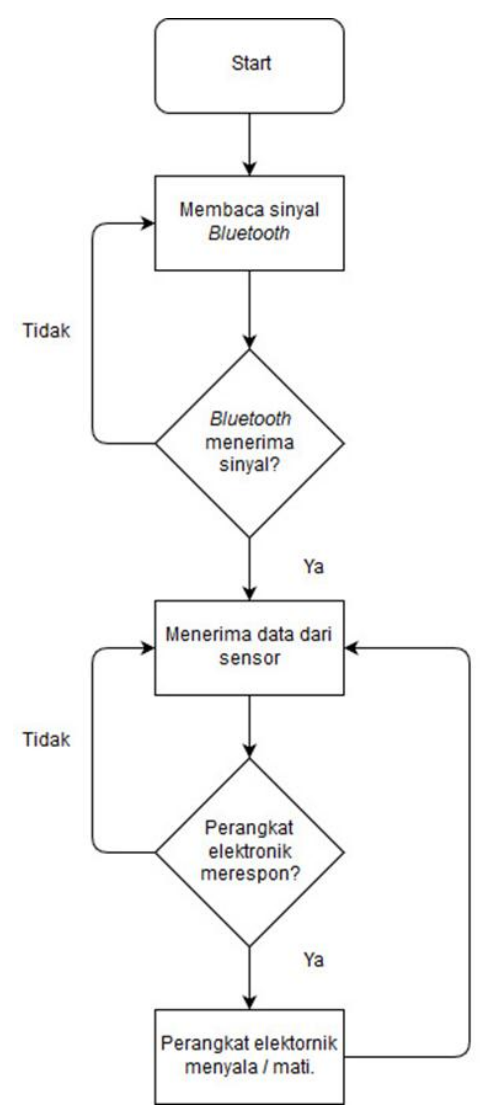

Gambar 5. Diagram Alir Alur Raspberry Pi

\section{Pengujian dan Pembahasan}

Pada tahap ini penulis melakukan implementasi alat Arduino Lilypad dengan mensolder semua pin yang digunakan pada sensor suhu, detak jantung, dan Bluetooth seperti yang ada pada gambar 6 .

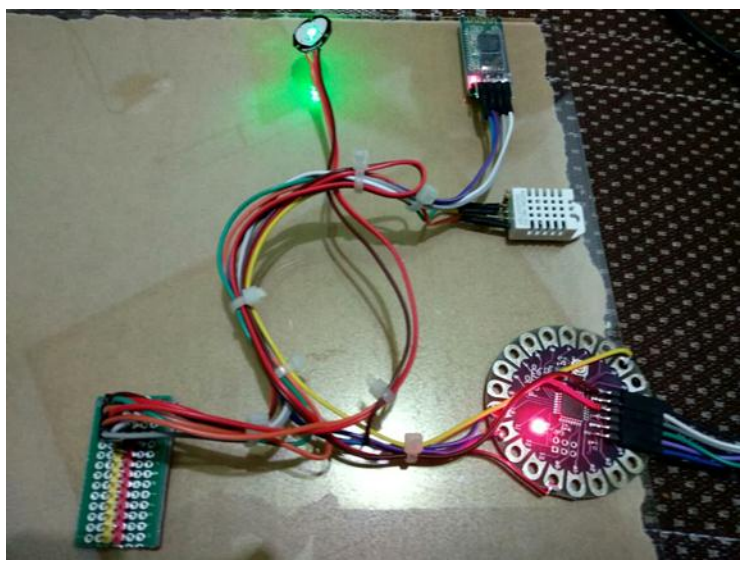

Gambar 6. Implementasi Arduino Lilypad

Pada implementasi untuk pengendali ruangan, 
digunakan 4 buah modul relay sebagai switch yang mengatur perangkat elektronik menyala atau mati. Relay tersebut dihubungkan dengan Raspberry Pi melalui pin GPIO seperti yang ada pada gambar 7 .

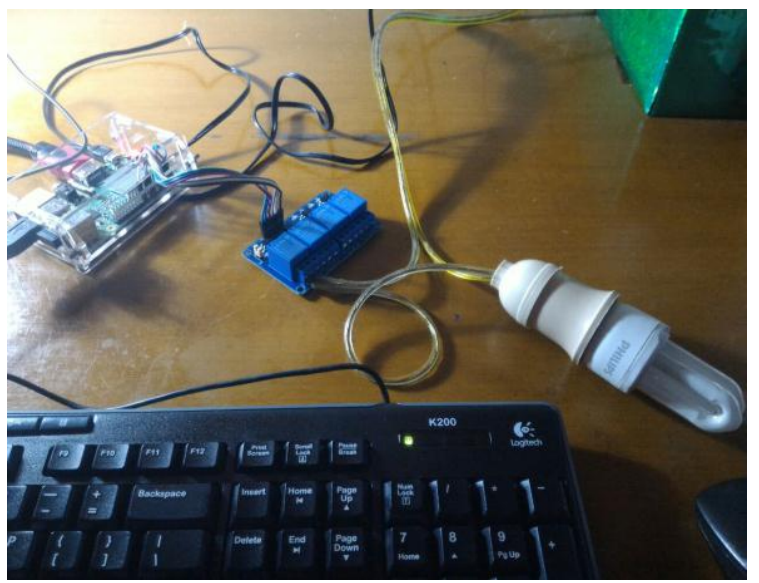

Gambar 7. Implementasi Rancangan Raspberry.

Pengukuran suhu pada sensor DHT22 dilakukan sesuai datasheet pada referensi yang digunakan penulis, pin yang digunakan pada modul sensor hanya pin VCC, Data dan GND. Pin Data terhubung dengan pin digital 2 pada Arduino Lilypad. Data yang dihasilkan oleh sensor suhu DHT22 berupa data real-time. pada tabel 1 ditunjukan hasil dari sensor DHT22 terhadap suhu dan kelembapan.

\begin{tabular}{cccc}
\multicolumn{4}{c}{ Tabel 1 Data sensor DHT22 } \\
\hline Waktu & $\begin{array}{c}\text { Suhu } \\
\left({ }^{\circ} \mathrm{C}\right)\end{array}$ & $\begin{array}{c}\text { Kelembapan } \\
(\%)\end{array}$ & $\begin{array}{c}\text { Keterangan } \\
\text { Kipas }\end{array}$ \\
\hline $08-08-$ & & & \\
2018 & 30 & 40 & On \\
$15: 26: 27$ & & & \\
$08-08-$ & & 39 & Off \\
2018 & 29 & & \\
$15: 30: 28$ & & & \\
\hline
\end{tabular}

Pada tabel tersebut dapat dilihat, kipas akan menyala jika suhu mencapai $30^{\circ}$ Celcius. Ketika suhu dibawah $29^{\circ} \mathrm{Celcius}$ kipas akan otomatis mati.

Hasil dari data detak jantung menunjukkan kondisi yang berbeda-beda, tergantung kondisi pengguna saat itu. Pada tabel 2 ditunjukan data dari detak jantung.

Tabel 2. Data detak jantung dalam satuan per-menit

\begin{tabular}{ccc}
\hline Waktu & BPM & $\begin{array}{c}\text { Keterangan } \\
\text { Lampu }\end{array}$ \\
\hline $08-08-2018$ & 50 & On \\
$15: 26: 27$ & & \\
$08-08-2018$ & 48 & Of \\
$15: 27: 27$ & 48 & \\
\hline
\end{tabular}

Detak jantung normal manusia rata-rata 50-70 kali per menit. Jika detak jantung lebih dari 70 kali per menit, maka kemungkinan seseorang mengalami gangguan kesehatan dibagian jantung. (Zhang, D., et al, 2016). Oleh karena itu penulis memilih detak jantung dengan kondisi 50 atau > 50 detak per menit sebagai acuan jika lampu menyala, dan memilih kondisi 48 atau $<50$ sebagai parameter untuk mematikan lampu.

Semakin rendah detak jantung seseorang, semakin rendah tingkat kesadaran sehingga penulis berasumsi untuk menjadikannya parameter otomatisasi perangkat elekrtonik lampu.

\section{Kesimpulan}

Pada penelitian ini telah dibuat sistem untuk memantau kondisi tubuh untuk mengendalikan perangkat elektronik yang ada pada ruangan. Kondisi tubuh dapat dipantau menggunakan sensor yang terpasang pada Arduino Lilypad dapat diterima oleh Raspberry Pi menggunakan Bluetooth sebagai perantara. Data yang dikirimkan ke Raspberry Pi digunakan untuk parameter pengendalian perangkat untuk menyalakan atau mematikan elektronik. Dari hasil pengujian didapatkan, ketika kondisi suhu naik, maka kipas akan menyala otomatis, hal ini berlaku sebaliknya. Untuk parameter pengendali lampu, dilihat pada kondisi detak jantung per menitnya. Ketika detak jantung mencapai $50 \mathrm{bpm}$ (beat per minutes) lampu akan menyala, hal ini juga berlaku sebaliknya

\section{DAFTAR PUSTAKA}

Chris Otto, Aleksandar Milenkovic, Corey Sanders, and Emil Jovanov. 2006. System architecture of a wireless body area sensor network for ubiquitous health monitoring.Journal of Mobile Multimedia1. 4.

MARYAM, N. N., Istiyanto, J. E. 2005. Menuju konsep Pervasive pada rumah cerdas:: Studi kasus Pengontrol Akses Pintu, Doctoral dissertation, Universitas Gadjah Mada.

Obaidat, MS, Denko, M., \& Woungang, I.. Pervasive Computing and Networking. Hoboken, NJ: John Wiley \& Sons, 2011.

Priyanka, R., Kamal D.S., Hakima C. dan Jean M.B. 2014. Wireless sensor networks: a survey on recent developments and potential synergies. The Journal of Supercomputing, April 2014, Volume 68, Issue 1, pp 1-48

Salayma, Marwa, et al. "Wireless Body Area Network (WBAN): A Survey on Reliability, Fault Tolerance, and Technologies Coexistence." ACM Computing Surveys (CSUR) 50.1 (2017): 3.

Samaneh Movassaghi, Mehran Abolhasan, Justin Lipman, David Smith, and Abbas 
Jamalipour. 2014. Wireless body area networks: A survey. IEEE Communications Surveys and Tutorials 16, 3, (2014)

Zhang, D., \& Shen, X., \& Qi, X. "Resting heart rate and all-cause and cardiovascular mortality in the general population: a meta-analysis. CMAJ : Canadian Medical Association Journal." 2016. 188(3), pp. E53-E63. 